\title{
PROTESTA DE LOS POSEEDORES DE MAYORAZGOS
}

\author{
Juan Francisco de Larrain y otros
}

* Imprenta de R. Rengifo. 1828. Santiago. Colección Domingo Edwards Matte. Archivo Central Andrés Bello, Universidad de Chile. 


\section{EXMO. SENOR.}

C

UANDO en el siglo en que se proclaman tanto las garantras individuales, vemog burladas nuestras esperanzas, quebrantados nuestros derechos, inutilizados nuestros afanes, y destruido para nosotros el principio fundamental de las asociaciones, no podemos dejar de protestar contra la resolucion que el Congreso constituvente acaba de tomar acerca de los mayorazgos de Chile. Protestamos del modo inas solemne para cual. quier tiempo en que á la justicia se tribute el homenaje debido. Protestamos contra todins $y$ cualesquier efecto que pueda producir la medida adoptada y esté en contra. diccion con nuestros derechos adquiridos. Protestamos=

Porque el Congreso constituyente es incompetente para dictar leyes de este jénero.

Porque la lei de mayorazgos no es lei fundamental, ni propia de una constitucion.

Porque si las constituciones del universo han contenido leyes mas 6 ménos di. verjentes del centro de los poderes, no estamos obligados á imitar este ejemplo, ni mé. nos potirá citarse una sola que presente un modelo semejante al artículo 121.

Porque la lei de mayorazgos no es lei de privilejio que afecte al órden político.

Porque si aquella es propia de una constitucion, lo serán mejor las leyes de viu. das, mcnores, militares, eclesiásticos y demas que envuelven privilejio.

Porque es una herejía politica decir que existe sobre la tierra un poder ilimitado.

Porque los hombres al reunise en sociedad ut sua tenerent spe custodia rerum suarum, ne ficiéron una cesion absoluta de sus derechos sino de aquella parte indispensablemente necesaria a la conservacion de la misma sociedad. Existen por lo tanto actos fuera de todn competencia social

Porque ese prurito de amoldarlo todo 6 wn tiempo enteramente nucto, nos conduce 4 aquel optimismo deplorable, que labró la rina de los tiberales de Espana, y comprometio la suerle de la Patria.

Porque los lejisladores constituyentes a mas de decretar el enajenamiento de los bienes vinculados, se han convertido en jueces partidores de la propiedad de aquellos, designando el tercio á los sucesores inmediatos.

Porque si a las nulidades reclamadas por los pueblos se nnaden infraceinnes de garantíns, nos esponemos á mirar con dolor que al código fundameatal presida una mala estrella, y lo acompane un hado el mas funesto.

Porque prescindiendo de las omisiones en las ritualidades del reglamento de debates, la abolicion ha sido sellada con el sufrajio de muchos diputados inmediatamente intercsudos en la mina de las vineulaciones. Se han hecho jueces en la causa en que cran notoriamente partes. Por ahora la decencia no nos permite revclar sus nombres.

Porque el artículo sancionado no salva el derecho á los nietos de los actuales poseedores y demas sucesores que hoi existen. Ningun proyecto presentado á nuestros anteriotes congresos ha tocado tal estremo: el senor Larrain en el de 23 salvaba en parte aun el derecho de los postumos.

Porque la resolucion actual no hace mencion de las pensionç $y$ obras pias afectas á todos los vínculos, sujetindolas tambien al pesado yugo de la abolicion.

Porque en el artículo acordado falta la bondad absoluta de las leyes, 4 que cede la relutiva de conveniencia $y$ circunstancia.

Porque se profana el sagrado de las últimas voluntades, respetadas en todos los pucblos cultos.

Porque se holla la facultad de disponer de los bienes que dió orijen a nuestras vinculaciones.

Porque obrando el hombre lo que la lei no prohibe, usa de las atribuciones que le detalla el código natural.

Porque si la lei civil puede coartar la facultad de disponer, ésta, léjos de emanar de aquella, tiene su asiento superior en la naturaleza que da al hombre un donaino absoluto sobre los objetos adquiridos per su fuerza fisica 6 moral.

Porque si el derecho de trasmitir la propiedad no es tan sagrado i por qué se con. servan las capellanias y patronatos? iCon que título poseen los poseedores? Si lo tienen en virtud de las fundaciones de hombres que dejáron de existir, respétese tam. bien el derecho adquitido por los sucesores á consecuencia de esas mismas fundacioncs que garantizan la posesion actual.

Porque solo hai dos títulos lejítimos de poseer: 6 adquirir por sí mismo, 6 recibir libremente de quien habia adquirido. ¿Con qué titulo los poseedores dispandrán 


\section{2}

de los biencs vinculados? Si con el de la lei ¡las disposiciones de los hombres habrín de ser los juguetes de las leyes!

Porque la propiedad entre todas las nacionos civilizadas es tan inviolable en las cosas que se poseen, como en el derecho á poseerlas. Si no se destruye en los actuales poseedores, tampoco puede serlo en los nacidos que existen con el derecho á suceder.

Porque el artículo 121 pugna con el 16, lo quebranta, to anula. El uno abole derechos lejitimamente adquiridos. El otro prescribe: "ningun ciudadano podrá ser privado de los biencs que posee, $\sigma$ de aquellos á que tiene lejítimo derecho. ni de una parte de ellos por pequena que sea, sino en virtud de sentencia judicial."

Porque se ajusta mui mal la cuenta de esperanzas enganadas incluyendo en ella los hijos de los poscedores, que no habiendo podido forjarse csperanzas sobre los bienes que no les pertenecian, no han recibido de las vinculaciones otra injuria que en. grosar su patrimonio con el usufructo de los bienes vinculados.

Porque es pueril preguntar cuales sean las leyes que aseguran los derechos futoros de los primojénitos, estando consignadas en los códigos que se han declarado vijentes por diversas disposiciones de nuestra sociedad: y han servido de norma á los tribunales de justicia para la decision de la multitud y diversidad de causas fa. lladas desde la declaracion de indepentencia.

Porque es de una trascendencia la mas perniciosa al orden social asegurar que al disolverse la sociedad, se anultaron do facto las leyes que la rejian. Si emancíationos del yugo cspañol, tambien nos emancipámos de las leves, nulas son las decisiones de los tribunales: nulos los pactos celebrados y garantidos por esas leyes cuya existencia se presumia y desapareció como el humo. i h $_{\mathrm{h}}$ no existen leyes! i Ui gentium sumus. in qua urbe sivimus, quam Rempublicam anbemus!!?

Porque ese imperio eminente, cse supremo dominio quo se ha querido conferir a las autoridades del estado, es una ranciedadian desconocida on el siglo de las lices, como propia del tiempo del sic volo, sic jubco, del tiempo de los reyes que se titula. ban señores de vidas $y$ haciendas: es un error cuyas desastrosas consecuencias nos conducirian $\hat{x}$ un haberinto mas intrincado que el de Dédalo, de donde no saldriamos ni con el hilo de Ariadna.

Porque jamas podrá santificarse la causa de la rapiña, aunquo se ocurra á escritores mercenarios cuyos papeles son las escrituras en que se solemniza el contrato do, ut des; son las respuestas de un abogado que defiende su pleito, no de un critico que pesa la materia en la balanza de la prudencia y la razon, son los escritos que bajo el velo de la imparcialidad ocultan la ponzona de la mala fe con que se ter. jiversan los dichos, se truncan los tesios, se desquician los argumentos para contestarlos á su salvo.

Porque es una omnipotencia abusiva $y$ prohibida por todos los principios natura. les, legales y políticos dar á las leyes efecto retroactivo; confundir las leves con sus usos, $y$ destruir actos $y$ derechos garantidos por leyes precxistentes. Un artículo tal, crecmos ocupe una pájina entre los derechos individuales segun la indicacion de un digno representante.

Porque es incontestable que los hombros no han consentido en las trabas de las loyes, sino para aplicar á sus acciones consecuencias ciertas, segun las cuales pudiesen dirijirse

Porque todas las propiedades sin excepcion perderian su garantía en un pais donde cada uno se viese espuesto á tales atentados, $y$ donde fuese posible abolir títulos fundados sobre leyes. Este es el verdadero punto de vista en que doben considerarse las vinculaciones existentes, $y$ al que se contrajo la comision de justicia informando al congreso de 23.

Porque el artículo protestado es un fallo ultra pelita Los mismos poscedores interesados en la destruccion de mayorazgos no han solicitado una redaccion tal, cualsa estampa en la parte del artículo que protestamos. Véanse sus observaciones de los años de 23 y 26.

Porque no se citará un ejemplo. de dentro 6 fuera de la América, de algun pro-yccto de lei, y ménos de alguna constitucion en que se hayan consultado tan poco como en el articulo protestado, los derechos adquiridos por los stecesores que existen.

Porque los principios politicos y económicos que se esponen en los libros contra la institucion de mayorazgos, son inadaptables al estado actual de Chile.

Porjue está confesado que en Chile no existe aristoctacia: que es una planta cryas raices jamas penetrarán en el suclo chileno. No podrá negarse que aquí no hai títulos, ni encomiendas, ni fendos, ni sefiorios jurisdiccionales, ni privitejios que desarreglen el sistema político, minen al órden social, $y$ hagan diferentes las condiciones entre los poseedores de un mayorazgo y el resto de sus conciudadanos.

Porque toda la desigualdad entre las vinculaciones y demas fortunas libres se redu. 
ce en último analisis á la posesion de una riqueza mas 6 ménos estensa, donada por la naturaleza á los llamados en las fundaciones respectivas, segun las trabas que los verdaderos y lejítimos dueños pudiéron imponer.

Porque no puede decirse sin estravagancia que hai desigualdad de derechos, cuando los ciudadanos de una misma sociedad celebran pactos bajo distintas condiciones, y todos y cada uno de ellos quedan sujetos a cumplir las cláusulas prescritas en sus obligaciones.

Porque la desigualdad de bienes siendo consecuencin de la diferencia que puso la naturaleza en las facultades físicas, morales é intelectuales de los hombres, subsistirá siempre contra el embate de las teorías, y los vanosesfuerzos que la intenten contener.

Porque el artículo sancionado viola ol principio supremo de la scguridad, que ordenando la conservacion da las esperanzas, prescribe que los acontecimientos en cuanto dependan de las leyes, sean conformes á las esperanzas que éstas han conducido.

Porque " cuando fa seguridad y la igualdad cstan en oposicion, no se debe dodar un momento, la igualdad es la que debe ceder; por que la primera es el fundamen. to de la vida: subsistencia, abundancia: felicidad, todo depende de ella; pero la igual. dad no produce mas que una porcion de bienestar.

Porque "si entre los intereses de estas dos rivales, la seguridad y la igualdad, hai oposicion, el único mediador es el tiempo. Si se quicren seguir los consejos de la igualdad sin contravenir á los de la seguridad, espérese la época que da fin á las es. peranzas $y$ á los temores, la época de la muerte.

Porque la sólida prosperilad de la agricultura consiste en que se posea una esten. sion considerable por personas que tengin capitales, 6 lo pucdan sacar de las mismas tierras para anxiliarse de máquinos, ariefactos y animales que multipliquen y faciliten el trabajo personal. De aque es que entre los pocos propietarios que hai en Chile capaces de éstos recursos, deben contarse precisamente los mayorazgos, como lo consen. ce la esperiencia.

Porque el defecto de cultura en Chile proviene de la falta de brazos y capita. les, sobrando una inmensidad de ticras para cuya ocupacion y cultivo convidariamos de buena gana j los estranjeros gratuitamente, $y$ aun colmándoles de privilejios.

Porque si la provincia de Sautiago donde existe el mayor número de vínculos está mas poblada y mejor cultivada que las otras donde no se conocen. inferirá cualquiera hombre que tenga dos dedos de frente, que en Chile las vinculaciones no impiden el cultivo.

Porque de nuestros fundos amayorazgados unos estan mejor cultivados que las fin. cas libres, $y$ otros no les ceden en cultura. Asf lo demuestra la esperiencia: y de aquí inferirémos sin violencia contra las teorfas indijestas, contra los heohos de las naciones estranjeras mal aplicados al estado actual de nuestro pais, que el cultivo no es incompatible con la cstension vinculada.

Porque es necesario alucinarse para creer que la baja del precio de las tierras será el primer efecto de la enajenacion de cuatro fundos, existiendo provincias enteras cu. yas tierras desocupadas se venden a un precio que ha tocado la línea de lo inereible.

Porque para que cesasen los celos de las provincias y las declamaciones de los cconomistas contra el engrandecimiento de las capitales, seria una medida de convenencia social alejar del centro la poblacion, y situarla en las provincias. Alli se ofrecen a manos llenas terrenos estensos $y$ mas pingües que los que se creen vendidos 5 un precio que parece tan alto.

Porque cuando oimos que la ventura de Chile y los adelantos de su poblacion de. penden de la division de las propicdudes, preguntamos 2 de qué propiedades se habla? Si de las libres: no es esta la cuestion. Si de las vinculadas: aquel tenguaje será propio de un escritor acostumbrado á ver el semillero de las vinculaciones de la Espana. donde el que tenia 200 ducados (como dice Campomanes) ya trataba de fundar un mayorazgo.

Porque en Inglatera á pesar de su escaso territorio $y$ de la multitud de vinculaciones de que esta llena, no se han impedido los adelantos de su riqueza, ni los progresos de su vasta poblacion. Higase el paralelo entre aquella Isla y nuestro Chile, y no podrá concebirse que Chile se despuebla por la existencia de 17 mayorazgos.

Porque la poblacion de Francia segun los datos de Peuchet corresponde á 1094 personas por legua cuadrada: la de Chile á 58 en el supuesto dudoso de que tenga un millon de habitantes, $y$ su estension solo sea de 17000 leguas cuadradas que es el cálculo mas reducido que se encuentra. De consiguiente necesita Chile cien anos para que su poblacion se nivele is la que hoi tiene la Francia, aun jirando el cálculo en progresion jeométrica sobre el supuesto que se doble cada treinta anos, como sucedió en Filadelfia. $y$ en el de que jamas atrasen tal progreso la guerra, emigracion, peste. hambre, $y$ demas azotes que aflijen la humanidad. A la Francia sin embargo no le han servido de estorbo las vinculaciones de que está plagada (á pesar de la discusion en la cámara de Pares, $y$ diputados del ano 26) para arribar á ese inmenso grado 


\section{4}

de poblacion, y ser uno de los paises que proporciona mas comodidades a la vida. $i \mathbf{Y}$ creerémos que la institucion de mayorazgos produce la despoblacion de Chile ! C Crecré. mos que la poblacion de Chile depende do la division de cuatro fundos vinculados! i Ah! Sin abolir mayorazgos no se puebla Chile, esto es, digámoslo sin rebozo, no se puebla el bolsillo.

Porque cuardo fuese tan evidente el interes público de la abolicion de mayorazgos $y$ tan necesaria $y$ urjente la division $y$ enajenamiento de sus terrenos, babian para realizar esto muchos modos ménos ruinosos, $y$ que en cierta forma conciliasen los de. rechos de los sucesores con la voluntad de los instituyentes, Cantos ejemplos nos han suministrado las lejislaturas de esta América! Cuantos prorectos en los congresos de 23 y 26 ! Dividanse enhorabuena los fundos vinculados si posible ca en trozos enajénense si se quiere al antojo de los actuales posecdores: pero conciértanse en un patronato: capitaficense sus valores en forma de capellania para que sus réditos se hagan efectivos á favor de los llamados por las fundaciones de dichos vínculos. Ho aquif un medio en que la division y enajenamiento exijido por ese decantado interes público, se conciliaba en cierta forma con los dercehos de los sucesotes, y voluntad de los instituyentes.

Porque. Pero i adonde nos conducirian nuestros reparos si quisieramos presentarlos en detalle! Este esqueleto de breves indicaciones no es el tipo, ni el libro de nuestras observaciones, sino la protesta contra la resolucion tomada que en todo tiempo servirá de garante á nuestros derechos y de apoyo á las reclamaciones de nucstra posteridad.

El tiempo que consume los prestijios $y$ descubre las intrigas, preguntará usando el lenguaje de un profundo político $i$ qué se hace para enganarse á sí mismo, 6 enganar al pueblo, y paliar las grandes injusticias? Se recurre a ciertas maximas pomposas que tienen una mezcla de verdad $y$ de falsedud, $y$ que dan á una cuestion sencilla en si misma un aire de profundidad y de misterio politico. El interes dó los in. dividuos, se dice, debe ceder af interes público: pero iqué significa esto en la materia que tratamos? iUn individuo no es parte del público, como otro individuo? El interes público que se preconiza, no es mas que un termino atstracto, que solamente representa la masa de los intereses individuales. Si fuera bueno sacrificar los bienes de un individuo para aur atar los de otros, aun seria mejor, sacrificar dos, tres, ciento, mil, sin que pueda semtarse límite alguno, pórque cualquiera que sea el número de los perjudicados, siempro habia la mistma razon para anadir uno mas; en una palabra, 3 et interes del primero es sagrado, 6 bo lo es el de ninguno.

El tiempo dirs: en machas ocasionet algunos hombres perjudicados por la opera. cion de una lei, no se han ntrevido a hablar, 6 no han sido escuchados por la oscura y falsa nocion de que el interes particular debe ceder al interes público; pero si se tratara de jenerosidad / quien deberia mejor excederla? ¿Todos con uno solo, ó uno solo con todos? Cual es el peor egoista, el que desea conservar lo que tiene, 6 el que quiere apoderarse aun por fuerza de lo que es de otro? Un mal que se siente, $y$, un beneficio que no se siente, este es el resultado de las grandes operaciones por las cunles son los individuos sacrificados al páblico.

EI tiempo anunciará, que cuanto mas se respete el principio de la propiedad, tan. to mas se afirma en el espiritu del pueblo. Los pequenos atentados contra este principio preparan los mayores. Ha sido necesario que pase mucho tiempo para llevarle al punto en que le vemos en las sociedades civilizadas: pero una fatal esperiencia nos ha hecho conocer con cuanta facilidad puede ser alterado, y mirar con horror las desastrosas consecnencias de tales alteraciones.

V. E que ha tenido la paciencia de escuchar nuestros acentos, tendrá la bondad de oir nuestras súplicas, $y$ usando de las atribuciones inherentes al poder ejecutivo designadas en varias lejes, y espresas en el artículo 82 del proyecto mismo de que se ocupa nuestro actual Congreso, se dignará hacer las observaciones que estime con. venientes sobre la parte del artículo que protestamos. V. E. es la áncora de nuestras esperanzas: la tabla en que se salvarin nuestros derechos del naufrajio en que se in. tentn sumerjirlos=Santiago agosto 3 de 1828 -Juan Francisco de Larrain=José Agus. tin Valdes=Francisco García Hurydobro=José Mfigael Irarrázaval=Manuel José Valdivieso. =Como apoderado de don Eujenio Cortés y Azúa Francisco de Borja Valdes.

IMPRENTA DE R. RENGIFO. 